\title{
Formation of porous zinc nanosystems using direct and reverse flows of DC magnetron sputtering
}

\author{
V.M.Latyshev, V.I.Perekrestov, A.S.Kornyushchenko, I.V.Zahaiko \\ Sumy State University, 2 Rimsky-Korsakov Str., 40007 Sumy, Ukraine
}

Received October 28, 2016

\begin{abstract}
The work is devoted to comparative analysis of two technological solutions for $\mathrm{Zn}$ nanosystems formation which have been implemented on the basis of direct-current magnetron sputtering. In the first case, conventional magnetron sputtering was used and direct flows were deposited on the substrate positioned in the front of a sputterer. In the second case, reverse flows were used and the substrate was located inside the magnetron sputterer. It has been shown experimentally, that the second technological approach gives more reproducible results as compared to the classical one. In addition, usage of the reverse flows leads to significant increase in the nanosystems deposition rates.

Keywords: metals, zinc, nanomaterials, magnetron sputtering, crystal morphology.

В работе проведен сопоставительный анализ двух вариантов структурообразования наносистем Zn. В первом классическом варианте формирование наносистем происходило на подогретых подложках, которые расположены перед магнетронным распылителем. Второй вариант основан на конденсации обратных диффузионных потоков распыленного вещества на подложки, которые расположены в полости магнетронного распылителя. Показано, что по сравнению с классическим вариантом, использование обратных диффузионных потоков приводит к более высокой воспроизводимости технологического процесса и к существенному повышению скорости наращивания наносистем.
\end{abstract}

Формування наносистем цинку з використанням прямих та обернених потоків магнетрона на постійному струмі. В.М.Латишев, В.І.Перекрестов, Г.С.Корнющенко, I.В.Загайко.

У роботі проведено порівняльний аналіз двох механізмів структуроутворення наносистем Zn. у першому класичному варіанті формування наносистем відбувалося на підігрітих підкладках, які розташовані перед магнетронним розпилювачем. Другий варіант заснований на конденсації обернених дифузійних потоків розпиленої речовини на підкладки, які розташовані у порожнині магнетронного розпилювача. Показано, що у порівнянні з класичним варіантом, використання обернених дифузійних потоків призводить до більш високої відтворюваності технологічного процесу і до суттєвого підвищення швидкості нарощування наносистем.

\section{Introduction}

It is known, that metal nanosystems are of great interest due to wide range of potential applications in sensors $[1,2]$, catalysts $[3,4]$, electrodes in electrochemical batteries [5, 6], fuel cells [7] etc. Among different porous metal nanostructures, zinc in the form of nanowires is of high demand nowa- days [8-12]. Different deposition methods have been utilized in order to fabricate nanostructures. The most often, they are grown by vapor transport during thermal evaporation [13, 14], electrochemical deposition [15, 16], plasma-arc deposition [17], magnetron sputtering [18]. The majority of metal nanosystems formation technologies 
operate under near-equilibrium condensation conditions. Analysis of the literature data [13-18] has shown, that at decrease in zinc vapors supersaturation the nanosystems structure formation mechanism changes from micro-particles to the nanowires growth. As a the first approximation [19], a critically small value of relative supersaturation can serve as criterion of proximity to equilibrium:

$$
\xi=\left(n-n_{e}\right) / n_{e},
$$

here $n$ and $n_{e}$ are actual and equilibrium concentrations of adatoms above the growth surface, correspondingly. The actual concentration is determined by sputtered substance flow directed to the growth surface, and the equilibrium concentration is given by:

$$
n_{e} \sim \exp \left(\frac{-E_{d}}{k_{b} T_{s}}\right),
$$

here $T_{s}$ is the growth surface temperature, $E_{d}$ is adatoms desorption energy, $k_{b}$ is the Boltzmann constant [19]. Consequently, in the case of conventional magnetron sputtering, near-equilibrium condensation conditions for $\mathrm{Zn}$ nanowires formation can be implemented using week flows of the sputtered substance together with the high temperatures of the growth surface. In this way, low values of the supersaturation and as a result the low deposition rates were achieved by reducing the discharge power value $P_{w}$ and increasing the working gas pressure $P_{A r}$.

In our previous works [20-22] we have developed versatile method operating under near-equilibrium condensation conditions which allow porous nanosystems formation of any metal. However, that technology has two important drawbacks. The first one is caused by the fact that under the near-equilibrium conditions the depositing vapors pressure must be comparable with the equilibrium pressure value, which for majority of metals has very low values even at the high temperatures [19]. To solve this problem, it is necessary to deposit rather weak fluxes. As a result, the deposition rate takes relatively low values in this case. The second lack of the technology is because of under the near-equilibrium condensat ion conditions even slight changes in the technological parameters values can cause significant changes in the nanosystems structure formation mechanism. That is why the nanosystems formed by conventional condensation methods which utilize week de- positing fluxes are not uniform with respect to the thickness.

Therefore, in order to overcome these two problems, it is necessary to find out which technological conditions can lead to increase in the deposition rate and allows the nanosystems formation with uniform thickness. In our previous works, it has been shown, that the desired conditions can be implemented using accumulation of sputtered substance near the growth surface with simultaneous plasma influence onto the growth surface [23-25]. In has been experimentally proved, that using self-organization of the near-equilibrium conditions in plasma-condensate system, reproducible porous $\mathrm{Zn}$ nanosystems can be formed [26]. But, unlike traditional methods of zinc nanosystems formation, we have experimentally found existence of three zones of technological parameters such as the working gas pressure and the discharge power inside which the layers having identical morphology are formed. This fact confirms the high level of reproducibility of the nanosystems formed by our method [26]. In order to prove possibility of practical application of these porous structures, two-step technology of ZnO nanosystems formation has been developed [27]. The zinc nanosystems formed by accumulative plasma-condensate system were oxidized in pure oxygen atmosphere. The sensor tests towards hydrogen have shown that sensitivity of the ZnO porous layers was more than $50 \%$ at hydrogen concentration of $3000 \mathrm{ppm}$ in dry air [27].

That is why the aim of the proposed work is to compare the conventional condensation method utilizing week depositing fluxes in order to approach equilibrium with the method that uses self-organization of near-equilibrium condensation conditions. The described in the work physical processes, which take place at self-assembling of porous metal nanosystems, can have significant practical applications. The comparative analysis will be made in the terms of nanosystems growth rate, structural and morphological homogeneity, elemental and phase composition of the condensates. It will allow finding out and proving the advantages of our method with respect to conventional technologies.

\section{Experimental}

Schematic cross-section of the magnetron sputtering system is given in Fig. 1. Let's consider the main operation principles of the system. The basic elements of the device 
are a magnetron sputter 1 combined with a hollow cathode 2 . Zinc target 3 was sputtered in crossed electrical and magnetic fields. Erosion zone is denoted by position 4 . The magnetic field was created by a magnet system 5 . The porous structures were obtained by zinc vapor deposition from plasma onto substrates 6 or 7 . In the case of direct flows condensation, substrate 6 was used which was located on a heater 8 . For reverse flows condensation, substrate 7 was used which was positioned inside the hollow cathode 2 . It is necessary to point out, that all experiments were carried out at relatively high working gas argon pressures from 5 to $12 \mathrm{~Pa}$. Within this range, the directions of sputtered atoms motion follow the cosine rule [19]. It is known, that the sputtered atoms have rather broad energy spectrum from 1 to $30 \mathrm{eV}$ [19]. Because of energy exchange with the working gas atoms, the sputtered atoms thermalize that averages their energy [28]. After thermalization, they continue to move diffusively. As a result, at distanced from the target, which is thermalization length, a diffusive source of sputtered atoms appears. It is denoted by position 9 in Fig. 1 . The value of thermalization length depends on such parameters as the mass of atoms, discharge power and working gas pressure. For the technological parameters values used in our experiments, $d$ has values from 6 to $18 \mathrm{~mm}$.

On the second stage, the substance from a diffusive source 9 moves toward substrates 6 and 7. At the low discharge powers the substance flows directed to anode $J_{a}$ (direct flows) and to target $J_{t}$ (reverse flows) are determined by the following equations [13]:

$$
\begin{aligned}
& J_{a} \approx J_{s}\left(d / d_{t s}\right), \\
& J_{t} \approx J_{s}\left(1-d / d_{t s}\right),
\end{aligned}
$$

here $J_{s}$ is the sputtering rate; $d_{t s}$ is the distance between target 3 and substrate 6 (Fig. 1). Thereby, depending on values of $d_{t s}$ and $d$ the different deposition flows intensities directed to the substrates 6 and 7 can be obtained.

In the work [23] we give detailed description of the reverse flows condensation mechanisms. The mathematical modelling and the experimental results have shown [23-25] that at substance condensation on the substrate 7 positioned in the hollow cathode 2 inside of the magnetron sputterer the self-organization of steady-state small supersaturations occurs. Qualitatively, the

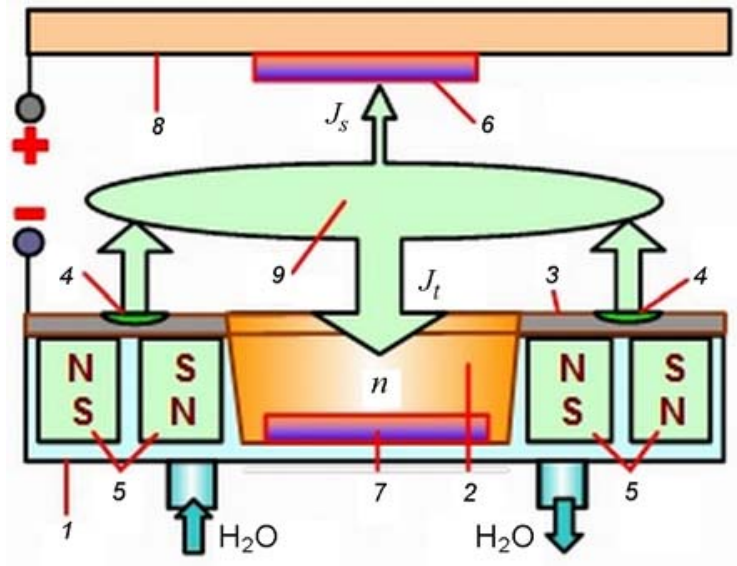

Fig. 1. Schematic cross-section of axisymmetrical sputtering system: 1 - magnetron sputterer; 2 - hollow cathode; 3 - zinc target; 4 - erosion zone; 5 - system of magnets; 6 - substrate for "direct flows" deposition; 7 - substrate for "reverse flows" deposition; 8 - anode with the substrate heater; $9-$ thermalization area of the sputtered atoms.

self-organization process is determined by non-linear interdependence between main technological parameters such as discharge power $P_{w}$, working gas pressure $P_{A r}$ and growth surface temperature $T_{s}$. At an increase in the discharge power $P_{w}$ simultaneous increase in the atoms concentration above the growth surface $n$ is observed. Due to the plasma action, the growth surface temperature $T_{s}$ increases too. According to (1) and (2) this interrelation stabilizes supersaturation at a constant level. Besides that, the intensity of depositing flows is self-regulated by diffusive motion of the sputtered atoms due to the heightened values of the working gas pressures. In this way, the reverse flow intensity is limited by decrease in the concentration gradient due to zinc accumulation above the growth surface inside the hollow cathode 2 . It is necessary to point out, that plasma density inside the hollow cathode 2 is approximately one order higher than the density of magnetron discharge plasma $[29,30]$. The substrate 7 is negatively biased, that is why ionized plasma atoms influence adatoms on the surface stimulating in such a way their re-evaporation. This process can be taken into account by decrease in the desorption energy $E_{d}$ value down to effective value [22]. This fact according to (1) and (2) additionally approaches the system to thermodynamic equilibrium.

In both sets of the experiments, in order to minimize influence of chemically active residual gases on the nanosystems forma- 
tion process, the working gas argon was subjected to deep purification according to methodology described in [31]. After the long-term purification, the total partial pressure of the chemically active gases was $8 \cdot 10^{-8} \mathrm{~Pa}$. Laboratory glass, pyroceramic, and $\mathrm{KCl}$ wafers were used as substrates. The composition, structure and morphology of $\mathrm{Zn}$ layers were investigated using transmission electron microscopy (Libra 200 FE TEM, Zeiss), scanning electron microscopy (REM-102E, SELMI) and scanning electron microscopy equipped with energy dispersive X-ray elemental analysis (SEM, FEI NanoSEM 230) and X-ray diffraction analysis (XRD, SIEMENS (2x) D5000 X-ray diffractometer).

\section{Results and discussion}

\subsection{Zn nanosystems structure formation} mechanism at direct flows condensation

In the first set of experiments, the influence of technological parameters on morphology of the layers at direct zinc flows deposition has been studied. The structure formation mechanism was effected by changing such parameters as discharge power $P_{w}$, working gas pressure $P_{A r}$, growth surface temperature $T_{s}$. Laboratory glass was used as a substrate material. It has been established, that the optimal parameters corresponding to size uniform zinc nanowires formation which have the smallest diameters are $P_{A r}=12 \div 15 \mathrm{~Pa}, P_{w}=30 \mathrm{~W}$, $T_{s}=150^{\circ} \mathrm{C}$ and deposition time $t \sim 1.5 \div 2 \mathrm{~h}$ (Fig. 2a). While using more prolonged deposition times, $3 \mathrm{~h}$ and longer, at the similar deposition parameters the nanowires become blurred and the growth rate decreases (Fig. 2b). The most probably, the deposition rate decrease is caused by additional growth surface heating under influence of secondary electrons coming out of the magnetron [19]. This fact leads to decrease in the relative supersaturation down to zero.

Variation of the working gas pressure from $12 \mathrm{~Pa}$ to $5 \mathrm{~Pa}$, while the rest of the parameters were kept unchanged, causes nanowires formation having the larger diameters. In this case, the diameter values scattering is more significant (Fig. 2c). According to (3) such changes in the morphology are determined by an increase in the direct flow intensity $J_{a}$ together with the relative supersaturation $\xi$ growth [17]. The increase in the working gas pressure from 12 to $15 \mathrm{~Pa}$ leads to significant decrease in the deposition rate. At the same time, the average diameter value decreases slightly.

Increase in the discharge power up to $50 \mathrm{~W}\left(P_{A r}=12 \div 15 \mathrm{~Pa}, T_{s}=150^{\circ} \mathrm{C}\right)$ leads to increase in the sputtering rate $J_{s}$ and following growth of the direct flow intensity $J_{a}$ and the relative supersaturation $\xi$. As a result, the thicker nanowires grow in this case. At the same time, the diameter values scattering increases significantly. The condensates morphology approximately corresponds to the structure shown in Fig. 2c.

It is necessary to point out, that even relatively small alteration of the growth surface temperature $T_{s}$ at all the rest parameters constant, courses significant change in the morphology. For example, decrease in the temperature value from 150 to $140^{\circ} \mathrm{C}$ courses the morphology change equivalent to the decrease in the working gas pressure $P_{A r}$ three times (from 15 to $5 \mathrm{~Pa}$ ). At the same time, the deposition rate decreases significantly at the increase in $T_{s}$ up to $170^{\circ} \mathrm{C}$. In this case, two hours deposition leads to the base layer formation only, which does not fully cover the substrate. It consists of elongated structural fragments cover with newly formed nanowires (Fig. 2d).

Any catalysts have been used during zinc nanowires growth. They form according to the vapor-crystal growth mechanism. It is confirmed by the absence of droplets at their ends, which is characteristic of the vapor-liquid-crystal growth mechanism [33-35]. The nanowires growth mechanism is following, on the first stage atoms are adsorbed on all crystallographic planes of the growing crystal equiprobably. From the other hand, the probability of adatoms re-evaporation from the crystallographic plane depends on the desorption energy value. In turn, this energy is proportional to the amount of nearest neighbors that surround the adatom on the corresponding plane [19]. At small supersaturation values, the adatoms with small desorption energy values re-evaporate [23-25]. As a result, growth of the crystals occurs only in particular crystallographic directions leading in such a way to the selective formation of the nanowires.

\subsection{Zn nanosystems structure formation} mechanism at reverse flows condensation

At reverse flows condensation the structure formation mechanism was regulated by variation of the working gas pressure $P_{A r}$ and the discharge power $P_{w}$. In this case, increase in the working gas pressure causes corresponding increase in the relative super- 

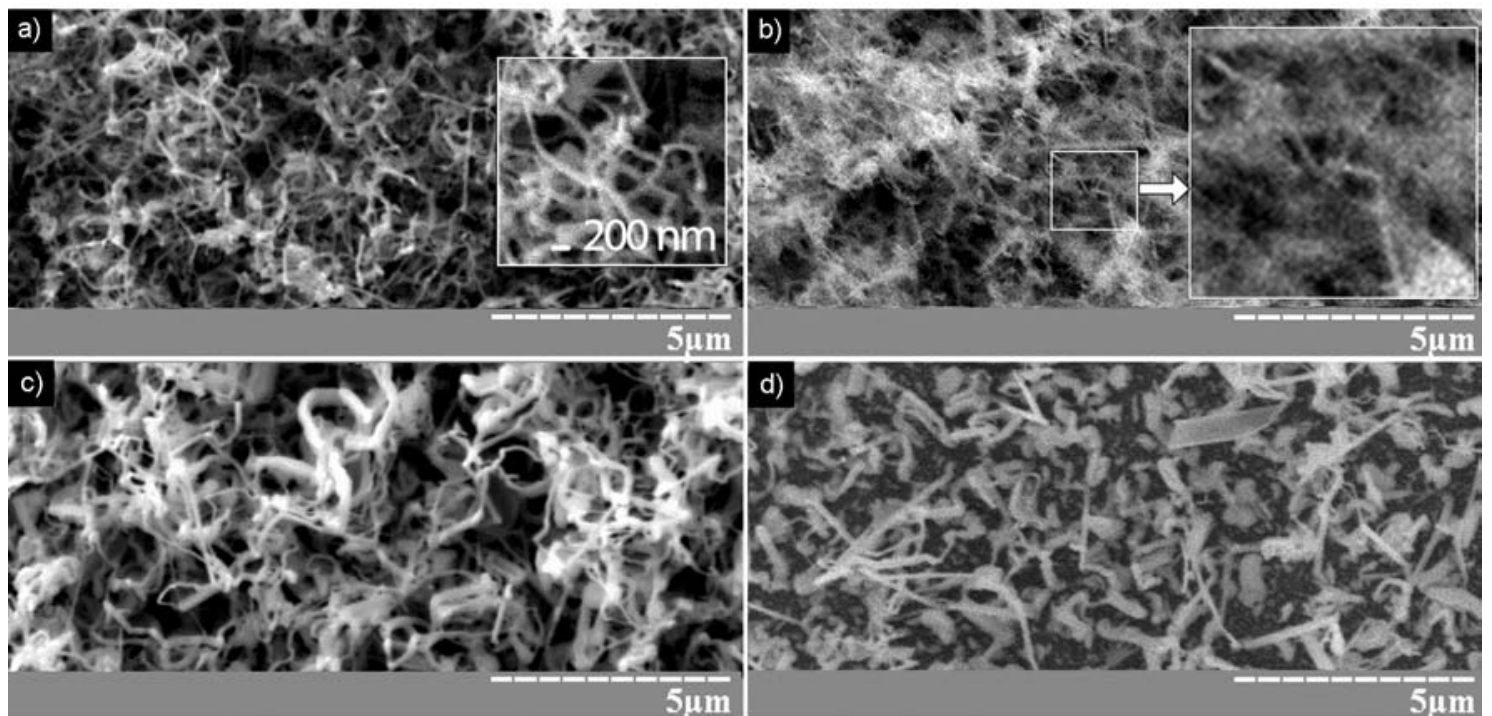

Fig. 2. SEM images of $\mathrm{Zn}$ nanostructures formed at direct flows deposition $\left(a-P_{A r}=12 \mathrm{~Pa}\right.$, $P_{w}=30 \mathrm{~W}, T_{s}=150^{\circ} \mathrm{C}, t=1.5 \div 2 \mathrm{~h} ; b-P_{A r}=12 \mathrm{~Pa}, P_{w}=30 \mathrm{~W}, T_{s}=150^{\circ} \mathrm{C}, t=3.5 \mathrm{~h}$;

$\left.c-P_{A r}=5 \mathrm{~Pa}, P_{w}=30 \mathrm{~W}, T_{s}=150^{\circ} \mathrm{C}, t=1.5 \div 2 \mathrm{~h} ; d-P_{A r}=12 \mathrm{~Pa}, P_{w}=30 \mathrm{~W}, T_{s}=170^{\circ} \mathrm{C}\right)$.

saturation value because of more intense scattering of sputtered atoms on the working gas molecules. At the same time, increase in the discharge power, as a rule, has little effect on the supersaturation value. This fact is the most characteristic difference between two technological approaches. The reason is that in the case of direct flows the growth surface is irradiated by electrons and in the case of reverse flows by ions. Due to the higher ions mass, heating of the growth surface is more intense in the latter case. As a result, the supersaturation growth is compensated by increase in the deposition flow. It is necessary to point out, that while using reverse flows there is no need in the substrate heating and regulating its temperature. The above-described features of the reverse flows condensation are confirmed experimentally in [23-27].

Fig. $3 a$ gives the layers morphology formed at relatively high supersaturation values obtained using the low discharge powers $\left(P_{w}=8 \mathrm{~W}\right)$ and heightened working gas pressures $\left(P_{A r}=12 \div 15 \mathrm{~Pa}\right)$. In this case, according to equation 4 the significant part of the sputtered flow forms the reverse diffusive flows $J_{t}$. At the same time, the growth surface heating due to ions bombardment of relatively low energy is insufficient. Consequently, the supersaturation value can be reduced by decrease in the working gas pressure $P_{A r}$ and by increase in the discharge power $P_{w}$. In order to establish how decrease in the supersaturation value influences zinc structural and morphological char- acteristics a following the set of experiments has been performed (Fig. $3 b, c, d$ ). It was shown, that decrease in the supersaturation value causes gradual transition from interconnected clusters formation (Fig. $3 \mathrm{~b}$ ) to nanowires system formation (Fig. $3 c$ ). This peculiarity is the second important distinctive feature of the reverse flows condensation. Due to ion bombardment of the growth surface, its temperature increases providing re-evaporation of great part of adatoms. In the vapor state they undergo ionization. In ionized state, they are directed to the growth surface under the electric field influence. The described above circular mechanism of mass-transfer provides accumulation of the substance near the growth surface.

As it follows from the mass transfer mathematical model [23], the circular masstransfer provides self-organization of steady-state small supersaturation values. For example, ion bombardment can cause a significant increase in the growth surface temperature. As a result, additional substance accumulation occurs above the substrate, which in turn stabilizes the supersaturation at a constant level. At the same time, increase in the discharge power causes simultaneous growth of the sputtered atoms flow and the plasma temperature [28]. At the heightened working gas pressures, the thermalization zone is located near the substrate surface. That is why additional plasma energy is transferred to the growth surface. This fact causes an increase in the 

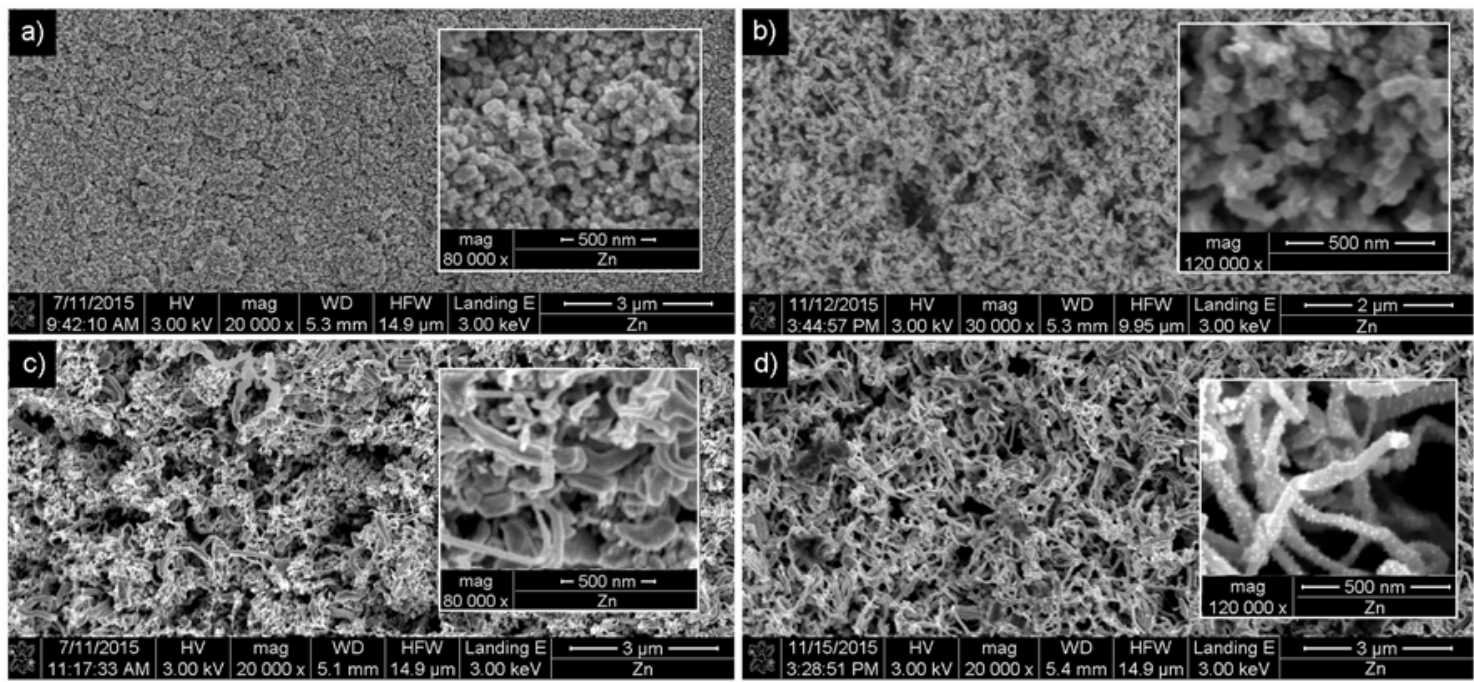

Fig. 3. Zinc nanostructures formed at reverse flows deposition on glass substrates $\left(a-P_{A r}=12 \div 15 \mathrm{~Pa}\right.$, $\left.P_{w}=8 \mathrm{~W} ; b-P_{A r}=8 \mathrm{~Pa}, P_{w}=12 \mathrm{~W} ; c-P_{A r}=7 \mathrm{~Pa}, P_{w}=18 \mathrm{~W} ; d-P_{A r}=6 \mathrm{~Pa}, P_{w}=22 \mathrm{~W}\right)$.

growth surface temperature and following decrease in the supersaturation down to the value which corresponds to the zinc nanowires formation.

\subsection{Comparative analysis of the techno-} logical approaches

\subsubsection{The nanosystems growth rate}

In order to compare the nanosystems growth rate at usage of direct and reverse flows, the corresponding layers cross-sections have been investigated (Fig. 4). In the both cases, the deposition time was $10 \mathrm{~h}$. From the thickness values it can be concluded, that the growth rate is four times higher at the reverse flows deposition (2.5 $\mu \mathrm{m}$ per hour) as compared to the direct flows. As it was already mentioned, the reduction of the growth rate in the case of the direct flows usage can be determined by additional growth surface heating by the secondary electrons at absence of self-organization of the critically small supersaturations.

3.3.2. The nanosystems structural and morphological homogeneity

The dimeter value uniformity of the nanowires obtained using the two technological approaches has been analyzed. It has been established, that in the both cases the uniform top layer consisting of nanowires with almost identical morphological characteristics is formed (Fig. $2 a$ and $3 d$ ). However, at the direct flows condensation a gradual decrease in the average nanowires diameter and in the deposition rate value is observed with increase in the layer thickness (insertion in Fig. 4b). From the other hand, usage of the reverse flows allows to obtain the nanowires with bigger diameter which are more morphologically homogeneous (Fig. 4a).

\subsubsection{Elemental and phase composition of the condensates}

The condensates phase and elemental composition has been investigated. The results of elemental analysis investigations have shown, that within the sensitivity range of EDAX for the both technological methods the freshly prepared $\mathrm{Zn}$ layers have no impurities. The analysis of X-ray diffraction patterns has shown that all diffraction maxima correspond to zinc with hexagonal lattice (Fig. 5). It is necessary to point out, that both for the direct and reverse flows phase and elemental composition corresponds to pure zinc.

3.3.4. Influence of substrate material on the structure formation mechanism

In work [4] it has been established, that thermal conductivity of the substrate material influences significantly the structure formation mechanism at the reverse flows condensation. This is a result of heating of the substrate by plasma and simultaneous cooling by running water (Fig. 1). That is why, in the case of $\mathrm{KCl}$ substrates usage, which has rather high thermal conductivity, the condensation process occurs at the higher supersaturation values. In this case, the layers have form of the nanowires systems with the thicker diameter values or the system of crystals with the quite large size. This problem can be solved by placing 


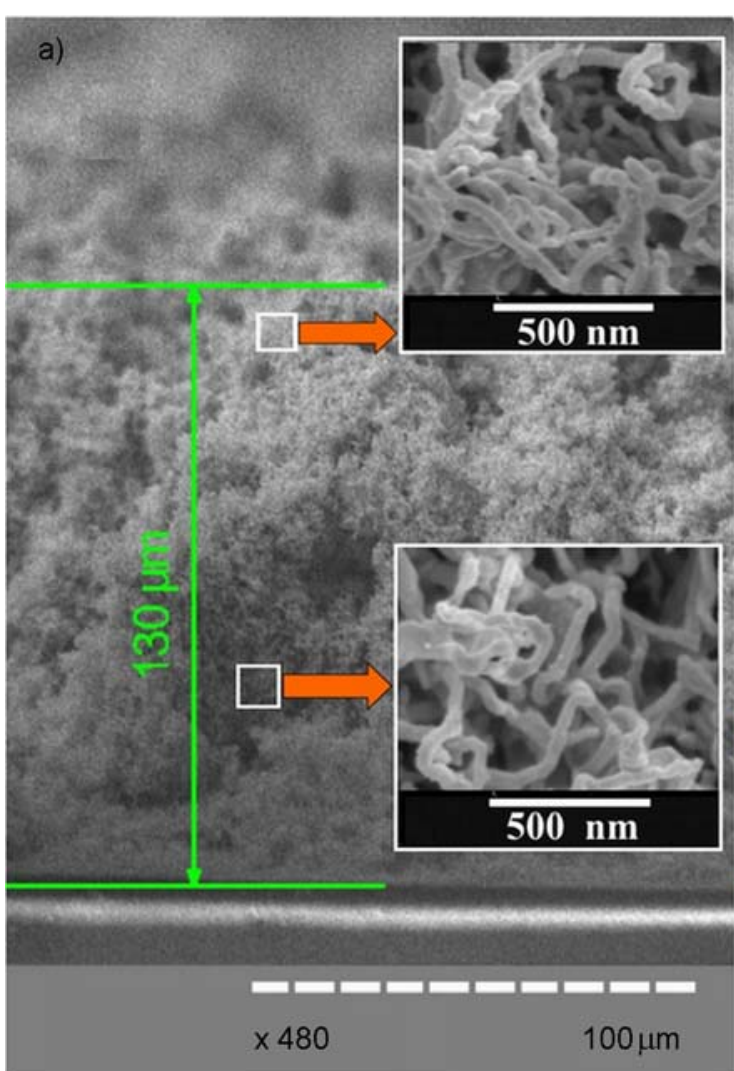

Fig. 4. Cross-sections of the layers formed at deposition during $10 \mathrm{~h}$.

the low thermal conductive material, isinglass for-example, between the substrate and the cooler. It was experimentally established that, the substrate surface structure and its thermal conductivity have no effect on the structure formation mechanism in the case of the direct flows deposition.

\section{Conclusions}

The main drawback of direct flows deposition is the fact that in this case zinc nanosystems structure formation mechanism is very sensitive to the growth surface temperature. That is why, the layers morphology changes during the growth process decreasing in such a way reproducibility of the nanosystems.

Thin zinc nanowires can be formed using reverse flows deposition. In this case, the required supersaturation value is achieved without heating of the substrate. On the one hand, this allows obtaining layers on the substrates having the low melting point. From the other hand, the equipment cost can be greatly decreased due to the absence of heating system and need of precise temperature control. The reproducibility of the layers is much higher as compared to the direct flows.

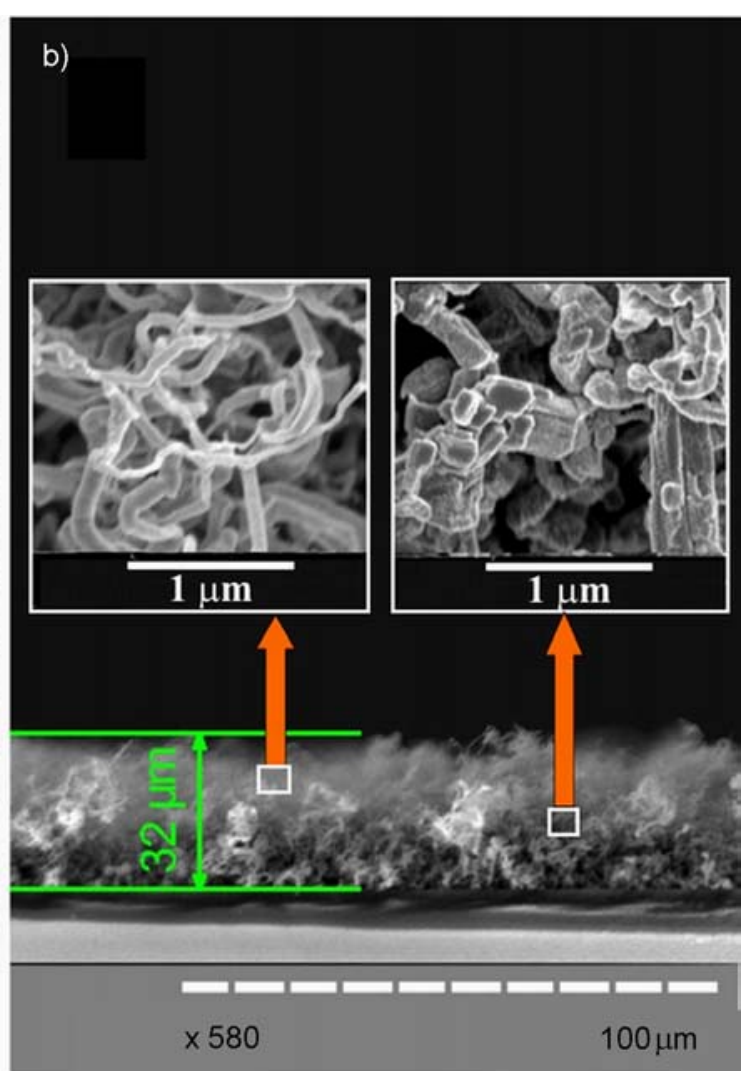

(a) reverse flows deposition and (b) direct flows
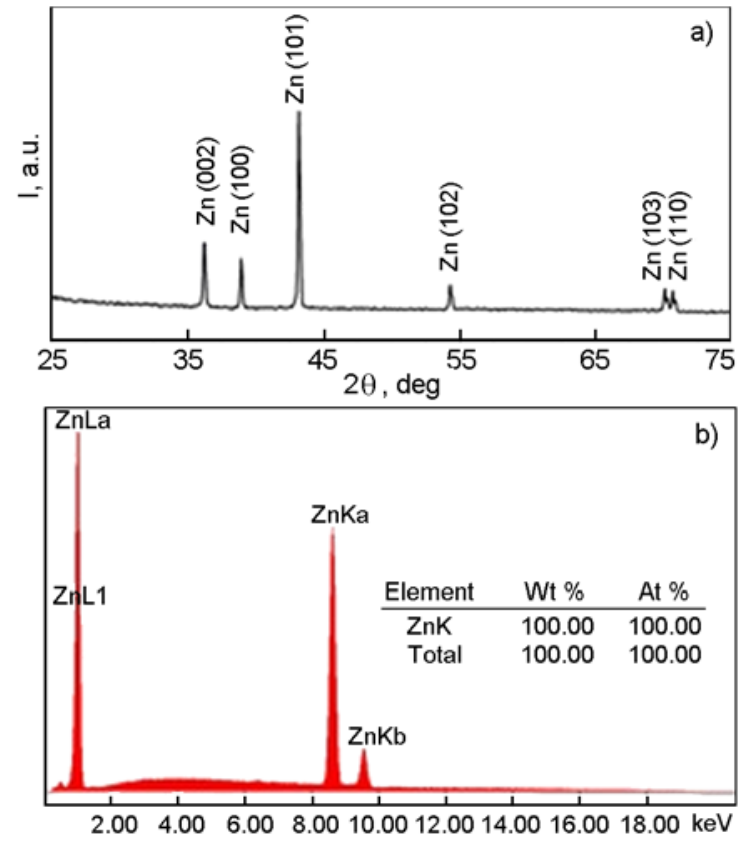

Fig. 5. XRD pattern (a) and EDX pattern (b) of zinc nanosystems.

The substance accumulation near the growth surface together with the self-organization of small supersaturation values at usage of the reverse flows allow to increase the deposition rate about four times 
as compared to the direct flows and also to obtain nanosystems having more homogenous morphology.

\section{References}

1. A.K.M.Kafi, A.Ahmadalinezhad, J.Wang et al., Biosens. Bioelectron., 25, 2458 (2010).

2. A.Abburi, N.Abrams, W.J.Yeh, J.Porous Mat., 19, 543 (2012).

3. K.Wegner, H.C.Ly, R.J.Weiss et al., Int.J. Hydrogen Energ., 31, 55 (2006).

4. V.Bansal, H.Jani, J.D.Plessis et al., $A d v$. Mater., 20, 717 (2008).

5. X.H.Huang, X.H.Xia, Y.F.Yuan et al., Electrochem. Acta, 56, 4960 (2011).

6. X.G.Zhang, J.Power Sources, 163, 591 (2006).

7. W.Yuan, Y.Tang, X.Yang et al., Appl.Energ., 94, 309 (2012).

8. D.Yuvaraj, R.K.Narasimha, K.Barai, Solid State Commun., 149, 349 (2009).

9. X.Wen, Y.Fang, S.Yang, Angew.Chem.Int. $E d .$, 44, 3562 (2005).

10. W.S.Khan, C.Cao, J.Zhong et al., Mater. Lett., 64, 2273 (2010).

11. B.Mun, D.Lee, Langmuir, 29, 6174 (2013).

12. R.Gazia, A.Chiodoni, S.Bianco et al., Thin Solid Films, 524, 107 (2012).

13. A.Khan, M.E.Kordesch, Physica E, 33, 88 (2006).

14. Y.J.Chen, B.Chi, H.Z.Zhang et al., Mater. Lett., 61, 144 (2007).

15. C.Fournier, F.Favier, Electrochem.Commun., 13, 1252 (2011).

16. D.Pradhan, S.Sindhwani, K.T.Leung, J.Phys. Chem.C, 113, 15788 (2009).

17. R.Cong, Q.Wang, J.Zhang et al., Chem.Phys., 129, 611 (2011).
18. S.Kim, M.C.Jeong, B.Y.Oh et al., J.Cryst. Growth, 290, 485 (2006).

19. L.I.Maissel, R.Glang, Handbook of Thin Film Technology, McGrawHillHook, New York (1970).

20. V.I.Perekrestov, Y.O.Kosminska, A.S.Kornyushchenko et al., Physica B, 411, 140 (2013).

21. V.I.Perekrestov, A.S.Kornyushchenko, V.V.Natalich, Solid State Sci., 33, 12 (2014).

22. V.I.Perekrestov, A.S.Kornyushchenko, Y.O.Kosminska et al., Appl. Surf. Sci., 316, 155 (2014).

23. V.I.Perekrestov, A.I.Olemskoi, Y.O.Kosminska et al., Phys. Lett.A, 373, 3386 (2009).

24. V.I.Perekrestov, A.S.Kornyushchenko, Y.A.Kosminskaya, Tech. Phys., 53, 1364 (2008).

25. V.I.Perekrestov, Y.O.Kosminska, A.S.Kornyushchenko et al., J.Porous Mater., 20, 967 (2013).

26. V.I.Perekrestov, A.S.Kornyushchenko, S.Ostendorp et al., Phys.Status Solidi B, 252, 397 (2015).

27. A.S.Kornyushchenko, A.H.Jayatissa, V.V.Natalich et al., Thin Solid Films, 604, 48 (2016).

28. A.G.Znamenskii, V.A.Marchenko, Tech.Phys., 43, 766 (1998).

29. M.M.Nikitin, Fiz.Khim.Obrab.Mater., 2, 27 (2011).

30. B.I.Moskalev, Discharge with Hollow Cathode, Energiya, Moscow (1969) [in Russian].

31. V.I.Perekrestov, S.N.Kravchenko, Instrum. Exp.Tech., 45, 404 (2002).

32. J.G.Han, J.Phys. D, 42, 043001 (2009).

33. V.Schmidt, S.Senz, U.Gosele, Phys.Rev. B, 75, 045335 (2007).

34. S.M.Roper, S.H.Davis, S.A.Norris et al., J. Appl.Phys., 102, 034304 (2007).

35. E.J.Schwalbach, P.W.Voorhees, App.Phys Lett., 95, 063105 (2009).

Formation of porous zinc nanosystems using direct and reverse flows of DC magnetron sputtering [T екст] / V.M. Latyshev, V.I. Perekrestov, A.S. Korniushchenko, I.V. Zahaiko // Functional materials. — 2017. — №24(1). - p. 154-161. 